$3^{\circ}$ INTEGRAR - Congresso Internacional de Arquivos,

Bibliotecas, Centros de Documentação e Museus

"PRESERVAR PARA AS FUTURAS GERAÇÕES"

\title{
Gestão das informações de produção científica institucional como preservação da memória
}

Thamyres Vieira dos Santos

Palavras-chave: Gestão da informação. Comunicação científica. Produção científica. Memória institucional.

\section{Introdução}

A informação é um ativo essencial nas organizações, seu gerenciamento eficaz deve ser realizado de maneira que seu armazenamento e recuperação possibilite apropriação pelos potenciais usuários. As informações relativas à produção científica de uma instituição são consideradas estratégicas uma vez que possibilitam estabelecimento de metas internas e externas, além do reconhecimento de si própria e de seus profissionais, gerando um histórico que pode ser utilizado como ferramenta de pesquisa para tomada de decisão de melhores práticas, preservando a memória organizacional e evidenciando as contribuições científicas em seu segmento de atuação. Dessa forma, este trabalho visa discutir como o gerenciamento das informações de produção científica institucional também se constitui como uma estratégia de preservação de memória, através de discussões que elucidem o papel desse gerenciamento, a importância e a consciência das instituições diante de tal atividade.

\section{Método da pesquisa}

Para levantamento bibliográfico foram utilizadas bases de dados como BRAPCI (Base de Dados Referencial de Artigos de Periódicos em Ciência da Informação), Scielo e 
$3^{\circ}$ INTEGRAR - Congresso Internacional de Arquivos,

Bibliotecas, Centros de Documentação e Museus

"PRESERVAR PARA AS FUTURAS GERAÇÕES"

repositórios institucionais. A partir dessa primeira busca foi possível identificar nas referências outros trabalhos com uma alta frequência de citação, evidenciando autores especializados e literatura relevante para a discussão. Em um primeiro momento o objetivo foi selecionar trabalhos que abordassem temas como gestão da informação nas organizações, comunicação científica e produção científica institucional. Em um segundo momento foi realizado um filtro de consulta para os trabalhos da área de administração e, majoritariamente, ciência da informação. Dessa forma, para embasamento, buscaram-se trabalhos que discutem questões relativas à memória organizacional. Após essas etapas se iniciou a revisão bibliográfica dos conceitos, e consequentemente a aplicação desses aos objetivos centrais dessa discussão.

\section{Discussão}

A informação científica tem como objetivo central a propagação em seu meio de atuação, visando contribuir na melhoria e desenvolvimento de processos, consequentemente no progresso da ciência. É fundamental destacar não somente a importância desse tipo informação em si, mas também de quem a produziu. Para que esse conteúdo seja recuperado é essencial a aplicação de estratégias de gerenciamento informacional de forma que, esses dados possam ser utilizados de maneira mais prática, visando fins internos e externos à organização. Internamente as informações podem ser consultadas a fim de contribuir para o estabelecimento de metas de produção de áreas específicas, estimulando um engajamento nas práticas científicas. Acomodar essas informações em ferramentas como repositórios institucionais, repositórios de e-prints, redes sociais científicas de acesso aberto, por exemplo, possibilitam que a comunidade acadêmica as acesse, tornando esse conteúdo passível de citação por novas pesquisas e trazendo reconhecimento à instituição e seus profissionais pela quantidade e qualidade de sua produção. Esse conjunto de informações se torna mais interessante quando analisado em um determinado período, ou seja, é importante considerar que esse registro deve ser feito 
$3^{\circ}$ INTEGRAR - Congresso Internacional de Arquivos,

Bibliotecas, Centros de Documentação e Museus

"PRESERVAR PARA AS FUTURAS GERAÇÕES"

pensado no uso em longo prazo, direcionado para a preservação dos conteúdos, focando em estabelecer um histórico institucional.

\section{Considerações Finais ou Conclusões}

As organizações compreendem a importância que suas informações possuem e acreditam que a solução para questões internas ou externas e aumento de reconhecimento da instituição em si e de seus profissionais está em seus próprios conteúdos produzidos. Preservar esse conjunto de informações de forma a torna-las recuperáveis conforme necessário contribuem para seu prestígio e ferramentas de armazenamento e estratégias de gerenciamento já são aplicadas em diversas instituições, desde universidades até as empresas.

\section{Referências}

DYRBY, S. S. What is information management? An investigation of meaning creation through discourse and construction. 2011. 139 p. Dissertação (Master on Business Administration and Information Systems: information management), Copenhagen Business School. Copenhagen, 2011. Disponível em:

$<$ http://studenttheses.cbs.dk/bitstream/handle/10417/3109/signe sofie dyrby.pdf?seque nce $=1>$. Acesso em: 5 nov. 2014.

FREIRE, Patrícia de Sá et al. Memória organizacional e seu papel na gestão do conhecimento. Revista de Ciências da Administração, Santa Catarina, v. 14, n. 33, p. 41-51, ago. 2012. Disponível em:

$<$ https://periodicos.ufsc.br/index.php/adm/article/view/21758077.2012v14n33p41/22535>. Acesso em: 04 maio 2016.

LEITE, Fernando César Lima; COSTA, Sely Maria de Souza. Gestão do conhecimento científico: proposta de um modelo conceitual com base em processos de comunicação científica. Ciência da Informação, Brasília, v. 36, n. 1, p. 92-107, jan./abr. 2007. Disponível em: <https://www.sct.embrapa.br/publicacoes/FernandoLeite Cl.pdf>. Acesso em: 18 abr. 2016. 
$3^{\circ}$ INTEGRAR - Congresso Internacional de Arquivos, Bibliotecas, Centros de Documentação e Museus "PRESERVAR PARA AS FUTURAS GERAÇÕES"

MCGARRY, Kevin. O contexto dinâmico da informação. Brasília: Briquet de Lemos, 1999.

MEADOWS, Arthur Jack. A comunicação científica. Brasília: Briquet de Lemos, 1999.

MUELLER, Suzana Pinheiro Machado. A ciência, o sistema de comunicação científica e a literatura científica. In: CAMPELLO, Bernadete Santos; CENDÓN, Beatriz Valadares; KREMER, Jeannete Marguerite. Fontes de informação para pesquisadores e profissionais. Belo Horizonte: Ed. UFMG, 2000.

VALENTIM, Marta (Org.). Gestão da informação e do conhecimento. São Paulo: Polis, 2008.

\section{Informações da autora}

Thamyres Vieira dos Santos

Bacharel em Biblioteconomia pela Escola de Comunicações e Artes da Universidade de São Paulo (ECA/USP).

Pós-graduanda em Teorias e Práticas da Comunicação pela Faculdade Cásper Líbero Email: thamyres.vieira@hotmail.com

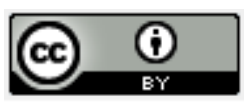

